\title{
The effects of low and high levels of vigilance on subsequent visual exploratory behavior in humans*
}

\author{
ROBERT L. DURHAM and JUM C. NUNNALLY \\ Vanderbilt University, Nashville, Tenn. 37240
}

Theoretical accounts of visual exploration have emphasized two classes of variables as important determinants of visual investigations: (1) the state of the organism and (2) the characteristics of the stimulus. While the latter class of variables has been investigated extensively, there is little, if any, literature concerning effects of organismic states on visual exploration. The present two experiments manipulated organismic states by having Ss perform repetitive vigilance tasks. The first study indicated that Ss who engaged in a highly repetitive vigilance task viewed complexity stimuli nearly twice as long as Ss engaged in a task requiring very little vigilance. The second study discounted the possibility that this effect was due to "time-off" behavior. The two studies open a new avenue for research in visual exploration.

In recent years, human exploratory behavior has received increased attention from researchers concerned with learning and motivation. Most research in visual exploration has examined the stimulus characteristics that elicit looking behavior, such as novelty and complexity (e.g., Berlyne, 1958; Faw \& Nunnally, 1967; Durham, Nunnally, \& Lemond, 1971; and Lemond, Durham, Slater, Wilson, \& Nunnally, 1972).

In most theoretical accounts of exploratory behavior, organismic states at the onset of exploration (e.g., activity, fatigue, etc.) are considered prominently; but almost nothing has been done to actually investigate the effects of such states on subsequent exploration. The prior states that have been discussed most frequently concern degree of arousal and degree of boredom. Berlyne, for one, has noted that boredom is "... likely when stimuli lack short-term novelty, i.e., when a stimulus is repeated many times in immediate succession [1960, p. 187]." Nunnally \& Lemond (in press) have noted that notions of arousal balance and boredom are closely related topics and that boredom occurs when the stimulus configuration is either impoverished or habituated. Practically all theorists have assumed that increased boredom will result in an associated increase in exploration (e.g., Glanzer, 1953; Myers \& Miller, 1954; Berlyne, 1960; and Nunnally \& Lemond, in press). The present two investigations attempt to manipulate the degree of boredom by subjecting Ss to two very

*The writing of this paper was supported in part by research grants from the National Science Foundation (No. GB29416) and the US Office of Education (No. OEG-4-71-0051) to J. C. Nunnally. The opinions expressed herein, however, do not necessarily reflect the position or policy of the US Office of Education and no official endorsement should be inferred. The paper was sponsored by Keith N. Clayton, who takes full editorial responsibility. different levels of a vigilance tack. Vigilance tasks in general are seen as relatively uninteresting repetitive tasks which correspond to Berlyne's notions of boredom. Also, vigilance tasks traditionally have been assumed to be relatively boring experimental situations (e.g., Smith \& Lucaccini, 1969).

In some studies of looking behavior, it has been the practice to place people in experimental settings of sensory isolation (e.g., Lemond et al, 1972). This practice, which later became a treatment condition, was originally instituted to allow Ss to calm down from their prior states of arousal (e.g., running across campus). In the series of studies reported by Lemond et al (1972), Es received the impression that Ss were not bored or aroused by the situation; rather, they were dropping off into fantasies about everyday activities. Thus, they were preoccupied with their own thought processes and apparently not highly bored or disturbed. On the other hand, a repetitive task (such as a vigilance task) should induce boredom and thus break up the opportunity to wander off into an interesting land of fantasy.

\section{EXPERIMENT I \\ Method}

The present investigation induced different states in two groups of Ss. The first group was kept busy with a vigilance task (HV), while the second group was given practically nothing to do (LV). To measure the relative amounts of boredom induced in the two treatment groups, one of three rating scales (e.g., "bored" to "interested") was given to each S. Ratings were taken at various points during the course of the study to assess changes in perceived boredom.

It was hypothesized that: (1) while both groups should become increasingly bored over the experimental session, the HV group should report greater amounts of boredom than the LV group, and (2) Ss in the HV condition should consequently look longer at stimulus configurations presented during break periods than $\mathrm{Ss}$ in the LV condition.

\section{Subjects}

The Ss were 42 male undergraduates enrolled in introductory psychology courses at Vanderbilt University. Participation was in partial fulfillment of a course requirement. Twenty-one Ss were assigned randomly to each treatment condition.

\section{Apparatus}

The experimental room contained an Industrial Acoustics Company acoustical chamber measuring $2.8 \times 2.1 \times 2.0 \mathrm{~m}$. Inside the chamber was a chair, a $1.9-\mathrm{m}$ table, an intercom, a 21 -in. television monitor, and a response switch mounted on a small metal box. The chamber was arranged so that $\mathrm{S}$ sat in the chair at one end of the table, while the television monitor rested on the other end of the same table. Outside the chamber, one closed-circuit television camera was focused on a screen which received flashes from an automatically timed tachistoscope. A second camera was focused on a screen upon which black and white slides were projected.

Each S sat in the chamber and viewed the stimuli that were 
Table 1

Average Ratings of Activity Collapsed Across Scales and Groups $\nmid$

\begin{tabular}{lllllllllllllllllllll}
\hline & \multicolumn{1}{c}{ Ratings } & \multicolumn{1}{c}{11.3} & 10.7 & $*$ & 10.6 & 9.8 & $*$ & 9.4 & 9.1 & $*$ & 9.0 & 8.3 & $*$ & 7.8 & 7.0 & $*$ & 7.0 & 6.5 & $*$ & 6.9 \\
\hline
\end{tabular}

†A low score represents decreased activity.

*Occurrence of each break period.

presented on the monitor. On the table in front of $\mathrm{S}$ was a switch which was used both to signal recognition of light flashes and to terminate slides shown during the break periods. These activities were registered on an event recorder outside the chamber. Except for the monitor and a small 25-W light, the chamber was dark during the experiment.

\section{Stimuli}

Two classes of stimuli were used in the present investigation. The first class consisted of flashes of light, produced by the t-scope, while the second class consisted of slides shown during the break periods. The flashes were centered on the television monitor and measured $25 \mathrm{~mm}$ in diam. Each flash remained on the screen for approximately $500 \mathrm{msec}$. For the HV condition, the flashes occurred an average of every $15 \mathrm{sec}$. These were arranged randomly throughout an interval between 10 and 20 sec. In contrast, Ss in the LV condition were told that only one flash would occur during the last $30 \mathrm{sec}$ of each vigilance period. Each vigilance period, for both treatment conditions, lasted exactly $4 \mathrm{~min}$. There were six periods of vigilance for each S.

The second set of stimuli consisted of randomly generated geometric forms (polygons), photographed on 35-mm achromatic slides and transmitted from the second camera. There were two stimuli at each of six levels of complexity (see Lemond et al, 1972 , for a discussion of figures and research employing them). The six levels of complexity were $3,10,20,40,80$, and 200 random turns, respectively. Ss in both treatment conditions were shown randomly six slides, one representing each level of complexity, viewing one slide per break period. A separate random order of presentation was used for each $\mathrm{S}$.

\section{Procedure}

Ss were tested in individual sessions which lasted between 30 and $40 \mathrm{~min}$. Ss were assigned randomly to treatment conditions ( $\mathrm{HV}$ and $\mathrm{LV}$ ) and one of three counterbalanced rating tasks. The three rating tasks employed were 20-point scales, ranging from "calm" to "agitated," "dull" to "excited," and "bored" to "interested." The most active score was 20 , while the most inactive score was 1 .

In both the HV and LV conditions, Ss were told explicitly when to expect the flashes. Ss were also given the impression that the full hour available for student participation would be consumed by this activity. To measure the relative amount of boredom perceived by Ss during the task, one of the three rating scales was given to each $\mathrm{S}$. The assignment of rating scales was counterbalanced so that a random one-third in each treatment condition received one of the three scales. In order to provide no hint about the length of the experiment, Ss were given many more rating sheets than would be needed. Each $S$ made 13 ratings: (1) an initial rating immediately following the instructions (after the $E$ left the chamber), (2) a rating after $3 \frac{1}{2} \mathrm{~min}$ had lapsed into each of the six vigilance tasks, and (3) a rating following each of the six break periods.

After $S$ was familiarized with the experimental chamber, he was placed in the chamber without a watch, books, or other potentially distracting personal items. $S$ was told that the investigation involved detection of light flashes under relatively isolated conditions. $S$ was told how long each trial block would be and (depending on the treatment condition) how of ten the flashes would occur. E then explained: "While I want you to be as accurate as possible in spotting the light, this is obviously very easy to do. Consequently, a major interest is in the effects on people of performing extremely simple, repetitive tasks like this." $S$ was then told of the rating tasks and their use, stressing the ratings as a crucial aspect of the experiment. After telling $S$ that a buzzer would indicate precisely when ratings were to be made, E said: "There will also be a break period following each 4-min trial block to give you an opportunity to rest from the task. Each break period will be signaled by the appearance of a picture on the screen. The pictures that will appear there were taken from other studies and are presented to give you something to look at during the break. When you are ready to go back to the task, press this same switch. This will terminate the break and the task will start again." Although these bland instructions were intended to minimize the importance of the amount of looking time at the pictures appearing during the breaks, actually the major purpose of the study was to determine whether looking time would be longer for the HV condition than for the LV condition. After $E$ left the chamber, he immediately gave $S$ the first rating signal and proceeded with the series of six vigilance periods and six break periods. Upon completion of the study, $\mathrm{S}$ was asked if he had any questions, after which he was excused from the experiment.

\section{Dependent Measures}

For each vigilance task, a record was kept of Ss' correct and incorrect responses. Since in both treatment conditions the task was made so simple that almost all responses were correct, these results were not analyzed further. Of primary interest was the amount of viewing time during the break period, which was converted from the event recorder tape to seconds of viewing time. These were employed in all subsequent analyses.

\section{RESULTS}

The amount of looking time during break periods was employed in a 2 by 6 analysis of variance. The two factors of that analysis were (A) treatment condition and (B) break periods. Factor A was a between-Ss factor and $B$ was a within-Ss factor. The analysis revealed only a significant effect due to treatment conditions $[\mathrm{F}(1,40)=6.738, \mathrm{p}<.02]$, with looking time for the HV group $(M=31.99 \mathrm{sec})$ greater than looking time for the $L V$ group $(M=16.67 \mathrm{sec})$.

Rating tasks were analyzed in a 2 by 3 by 13 analysis of variance-two treatment conditions, three rating scales, and 13 ratings. The first two factors were between-Ss factors, while the third was a within-Ss factor. An inspection of the means in Table 1 for 13 ratings suggested a decreasing trend. This was shown in a significant main effect $[F(12,432)=16.133, p<.001]$. The overall mean difference between the three scales was not significant; consequently, these data were not analyzed further.

\section{DISCUSSION}

The two treatment groups were distinguished clearly in terms of amount of looking time. In previous studies of looking behavior, it was unusual to find that one condition would result in almost twice as much looking time as another condition. However, the present study raised two issues which had not been 
anticipated initially. First, the two different treatments did not lead to different types of ratings of boredom. Second, only after the experiment was undertaken did it occur to the investigators that an important control group was not included. Ss in the HV condition could be construed to be engaged in an extremely unpleasant task. The longer amounts of looking time for the HV condition could represent a desire for "time-off" behavior rather than a desire for visual investigation per se. Consequently, Experiment II was designed to eliminate this potential alternative explanation of the results of Experiment $I$. If the longer looking time in the HV condition of Experiment I actually was due to a desire for "time-off," then it would be expected that Ss would look a relatively long time at anything during the break period, e.g., a blank screen.

\section{EXPERIMENT II}

Method

Experiment II replicated the HV condition in the first study and compared that treatment to an identical group shown asterisks instead of complexity figures during the six break periods. The rating scales were employed in the second study not for expected positive results but rather to keep conditions as nearly constant as possible to those in the first experiment.

Subjects

Thirty-six male undergraduates were assigned randomly to one of the two treatment conditions. Ss were drawn from the same introductory psychology classes as those in Experiment $\mathrm{I}$.

\section{Apparatus and Stimuli}

The apparatus was identical to that employed in Experiment I. The stimuli for the vigilance tasks were the same as for the HV task in Experiment I. The control group saw asterisks during the break periods, while the experimental group saw random orders of the same polygons as those used in Experiment I.

\section{Procedure}

With one exception, the procedure was identical to that employed in the HV group in the first study. When $\mathrm{E}$ explained the break periods to the control group, he said: "Each break period will be signaled by the appearance of an asterisk on the screen. The asterisks are presented to give you something to look at during the break." All other instructions and procedures were identical.

\section{RESULTS}

As in Experiment I, no S made more than one error on the vigilance task. The looking time scores for both the complexity slides and the asterisks were computed and employed in a 2 by 6 analysis of variance. The two factors were (A) treatment condition and (B) break periods. The first factor was a between-Ss factor and the second was a within-Ss factor. The looking time for the experimental group $(M=31.99 \mathrm{sec})$ was significantly greater than that for the control group $(M=8.81 \mathrm{sec})$ $[\mathrm{F}(1,34)=14.847, \mathrm{p}<.001]$. No other effect was significant.

As in Experiment I, the rating tasks were employed in a 2 by 3 by 13 analysis of variance. The factors were the same as those in Experiment I. The overall results from the rating tasks were as confusing as those in the first experiment: Different scales showed different results, with highly significant interactions between break periods, scales, and conditions. Since these significant findings were not consistent with each other and were considered uninterpretable, they will not be discussed further.

\section{DISCUSSION}

The first experiment showed a clear difference between two groups differing in amount of vigilance. The second stidy demonstrated clearly that the difference in the high-vigilance condition was not because of a so-called desire for "time-off." Since a postexperimental analysis indicated that the two HV conditions in the two studies were not significantly different, there is circumstantial evidence that the two sets of data are comparable. The overall results strongly suggest that amount of visual exploration of stimuli, such as those employed in these two experiments, is influenced by level of prior vigilance. Because only confusing results were obtained from the rating tasks, other types of reactions from Ss should be investigated in order to assess subjective reactions to the different experimental treatments. It should be emphasized that subjective ratings have not been employed previously in studies of exploratory behavior or in studies of vigilance. In contrast to the ratings, the measures of looking time have been employed in numerous investigations in the past, and, consequently, the findings in that regard tie in with the growing tradition of research on the determinants of looking behavior.

These two companion experiments mainly are important in providing one of the first steps in the investigation of prior states of activity on amounts and kinds of visual exploratory behavior. Now more parametric investigations of types and degrees of prior vigilance are needed.

\section{REFERENCES}

Berlyne, D. E. The influence of complexity and novelty in visual figures on orienting responses. Journal of Experimental Psychology, 1958, 55, 289-296.

Berlyne, D. E. Conflict, arousal, and curiosity. New York: M cGraw-Hill, 1960.

Durham, R. L., Nunnally, J. C., \& Lemond, L. C. The effects of levels of information conflict on visual selection. Perception \& Psychophysics, 1971, 10, 93-96.

Faw, T. T., \& Nunnally, J. C. The effects on eye movements of complexity, novelty, and affective tone. Perception \& Psychophysics, 1967, 2, 263-267.

Glanzer, M. Stimulus satiation: An explanation of spontaneous alternation and related phenomena. Psychological Review, $1953,60,257-268$.

Lemond, L. C., Durham, R. L., Wilson, W. H., Slater, G. P., \& Nunnally, J. C. The influence of varying degrees of complexity and sensory isolation on visual exploratory behavior. Unpublished manuscript, Vanderbilt University, 1972.

Myers, A. K., \& Miller, N. E. Failure to find a learned drive based on hunger: Evidence for learning motivated by "exploration." Journal of Comparative \& Physiological Psychology, 1954, 47, 428-436.

Nunnally, J. C., \& Lemond, L. C. Exploratory behavior and human development. In L. P. Lipsitt and H. W. Reese (Eds.) Advances in child development and behavior. Vol. 8. New York: Academic Press, in press.

Smith, R. L., \& Lucaccini, L. F. Vigilance research: Its application to industrial problems. Human Factors, 1969, 11 , 149-156.

(Received for publication February 8, 1973.) 